Research Article

\title{
Preparation and Anti-Icing of Hydrophobic Polypyrrole Coatings on Wind Turbine Blade
}

\author{
Bin Qu, ${ }^{1}$ Zhou Sun, ${ }^{1}$ Fang Feng $\mathbb{D}^{1,2,3}$ Yan Li ${ }^{1},{ }^{3,4}$ Guoqiang Tong, ${ }^{4}$ \\ and Rana Shahzad Noor ${ }^{4}$ \\ ${ }^{1}$ College of Arts and Sciences, Northeast Agricultural University, Harbin 150030, China \\ ${ }^{2}$ Key Laboratory of Icing and Anti/De-Icing of Aircraft, China Aerodynamics Research and Development Center, \\ Mianyang Sichuan 621000, China \\ ${ }^{3}$ Heilongjiang Provincial Key Laboratory of Technology and Equipment for Utilization of Agricultural Renewable Resources in \\ Cold Region, Harbin 150030, China \\ ${ }^{4}$ College of Engineering, Northeast Agricultural University, Harbin 150030, China
}

Correspondence should be addressed to Fang Feng; fengfang@neau.edu.cn

Received 7 October 2019; Revised 7 January 2020; Accepted 25 January 2020; Published 11 February 2020

Academic Editor: Ion Paraschivoiu

Copyright (C) 2020 Bin Qu et al. This is an open access article distributed under the Creative Commons Attribution License, which permits unrestricted use, distribution, and reproduction in any medium, provided the original work is properly cited.

This paper describes the method of preparing strong hydrophobic polypyrrole (PPy) on wind turbine blades. The water contact angle of strong hydrophobic PPy coatings was $127.2^{\circ}$. The strong hydrophobic PPy coatings exhibited excellent anti-icing properties. The maximum icing weight of strong hydrophobic PPy coating blade was almost $0.10 \mathrm{~g}$ while the maximum icing weight of no coating blade was found to be $26.13 \mathrm{~g}$. The maximum icing thickness of a strong hydrophobic PPy coating blade was only $1.08 \mathrm{~mm}$. The current research will provide a better technique to create anti-icing coatings on wind turbine blades and other outdoor equipment.

\section{Introduction}

Recently, wind energy has been developed greatly [1]. Moreover, the wind turbines operating in high altitude or cold areas are threatened by ice problems [2]. Accumulation of ice on the exposed surfaces can cause serious problems with the integrity of outdoor equipment [3]. The ice formed into the wind turbine blades cannot be eliminated in time, thus significantly reducing the performance of wind turbine $[4$, 5]. Initial ice creation changes the original aerodynamic profile of the blade; continued ice accretion can affect the structural loading of the entire rotor leading to potentially dangerous situations. Several anti-icings and de-icing systems have been developed in the past to avoid or reduce the ice formation on structures for the description of different ice protection systems [6]. Many active and passive methods in development have been presented to reduce or eliminate the icing on wind turbine blades, in order to decrease the economic loss caused by icing and assure the maximum reliability of the wind turbine blades [7]. The active techniques, such as thermal and mechanical methods, are used widely but have high-energy requirement and are expensive to operate $[8,9]$. However, the passive techniques such as anti-icing coatings are environmentally friendly and cheaper, which do not need any external energy to prevent ice accumulation $[10,11]$. Thus, developing anti-icing coating into wind turbine blades is the most reliable and cost-effective technique for icing effects $[12,13]$. Many researches on anti-icing coating have been conducted and made delightful progress $[14,15]$.

Due to the lotus effect, hydrophobic surfaces with greater water contact have gained great attention because of their potential biological and industrial applications [16]. The larger contact angle can effectively allow the droplets roll down on the surface of the object and make it difficult to freeze. A rough substrate minimizes liquid contact via nonwetted areas of trapped air [17]. At the same time, the gas inside the microstructure can prevent the heat, delaying the freezing time of the droplets falling on it. In addition, the 
hydrophobic interface can also change the crystallization process of liquid, such as reducing the freezing point and changing the type of crystallization. The liquid droplets form ice layers on the hydrophobic surface, which can obviously reduce the adhesion between them and make the ice layer fall off more easily. Thus, hydrophobic surfaces or coatings could be ideally potential anti-icing materials for protecting the outdoor equipment in cold seasons $[18,19]$. To take advantage of the role of hydrophobic coatings for anti-icing on the wind turbine blades, the preparations of hydrophobic coatings are crucial. Many studies [20-22] had been reported making hydrophobic or super-hydrophobic surfaces on different substrates. However, it is necessary to develop more new and facile methods of fabricating hydrophobic coatings on wind turbine blades.

Herein, a method was developed to prepare hydrophobic PPy coatings on wind turbine blades. The chemical compositions were analyzed by Fourier-transform infrared spectroscopy, the morphology and structure were analyzed by field emission electron scanning microscopes, and the wetting characteristics were analyzed by a contact angle-measuring instrument. In addition, wind tunnel experiments were carried out to analyze the surface dynamic freezing adhesion and ice resistance of polypyrrole hydrophobic coatings. It should be mentioned that the present method is very suitable for largescale preparation of hydrophobic coatings. Moreover, it has simple operation and the raw materials were cheap. In addition, the hydrophobic coatings on the wind turbine blades showed excellent hydrophobic and anti-icing effects.

In this work, commercial grade polyvinyl louden fluoride (PVDF, obtained from Harbin Lithium battery factory of China) was used without any further treatment. Wind turbine blades were obtained from Northeast Agricultural University, China. Analytical grade pyrrole, cetyltrimethyl ammonium bromide (CTAB), ammonium peroxydisulfate (APS), N-methyl pyrrolidone (NMP), and hydrochloric acid $(\mathrm{HCl})$ were purchased from Tianjin Zhiyuan Chemical Reagent Co., Ltd. (China). First, $1 \mathrm{~mL}$ pyrrole monomer, $2.02 \mathrm{~g}$ APS, and $1.1 \mathrm{~g}$ CTAB were added. During the polymerization process, the temperature was controlled at $0^{\circ} \mathrm{C}$ and the polymerization time was $12 \mathrm{~h}$. Finally, the products were cleaned repeatedly with water, ethanol and the vacuum drying.

\section{Test System}

Currently, the ice numerical simulation and ice wind tunnel test are the main methods to prevent and remove ice [23-27]. Ice numerical simulation was mainly applied to the numerical prediction of ice shape and the calculation of aerodynamic characteristics after ice formation. With the rapid development of CFD in the 1970s, a number of mature icing procedures have been developed in international aviation icing research groups, such as LEWICE (NASA in the United States), onice (ONERA in France), trajice (DRA in the United Kingdom), feap-ice (DTIC in Canada), Canice (Bombardier in Canada), and ciramil (CIRA in Italy) $[28,29]$, some of which have become a flying standard tool for the validation of icing airworthiness of vehicles.
An icing wind tunnel test is the main means of icing research. It can simulate the icing condition of icing objects in a cold environment more accurately by simulating various parameters in a real environment. It has the outstanding advantages of economy, practicality, advancement, and safety to study the icing and anti-icing characteristics [30]. In a sense, it does not need such a high-precision and high-cost icing wind tunnel to study the icing and antiicing problems of wind turbine blades, and the lowtemperature environment wind tunnel close to the natural conditions is more suitable. In order to study the icing characteristics of wind turbines and develop the anti-icing and deicing system, the authors' research office uses the unique low-temperature environment in Northeast China. The water mist injection system was installed on the basis of the conventional open jet wind tunnel and increased the experimental air channel, provides the icing environment conditions, controls the various environmental parameters of icing, and designs the wind turbine icing wind tunnel experimental system using the natural low temperature.

In this experiment, the natural cryogenic wind tunnel system, field emission scanning electron microscopy, video optical contact, angle measuring instrument, electronic balance, Fourier transform infrared spectroscopy, and other instruments were used. The natural cryogenic wind tunnel system is shown in Figure 1(a). The experimental section was completely transparent and observable, the size of which was $1 \mathrm{~m} \times 1 \mathrm{~m} \times 2.5 \mathrm{~m}$. The experiment model was installed on the blade rotation test bench, as shown in Figure 1(b). The natural cryogenic wind tunnel system can control the flow and particle size of water drop by adjusting the combination of wind speed, nozzle number, nozzle diameter, and water pressure.

\section{Experiment Model}

In this experiment, three blades of NACA 0018 airfoil made of glass fiber composites were used, which are often used on small wind turbines. As shown in Figures 2(b) and 2(c), the chord length was $125 \mathrm{~mm}$, and the width was $10 \mathrm{~mm}$, using PVDF coating, PPY anti-icing coating, and no coating. PVDF coating can be done directly on the surface and form a film. The weight ratio of PPy to PVDF in the PPy anti-icing coating was $1: 8$. After processing, a black viscous PPy mixture can be obtained. The viscous PPy was painted onto the wind turbine blades using a brush and dried in the air. After that, a wind turbine blade coated with PPy was dried in a vacuum at $60^{\circ} \mathrm{C}$ for $12 \mathrm{~h}$ to adequately evaporate. And then a hydrophobic PPy coating was obtained on a wind turbine blade.

\section{Results and Analysis}

4.1. The Chemical Composition Analysis. In this study, the chemical compositions of PPy were analyzed by Fourier transform infrared spectroscopy (ALPHA-T, Brooke Germany Ltd.). Figure 3 shows the FTIR spectrum of PPy, and the characteristic absorption peaks were shown. The three absorbance features in the $\mathrm{N}-\mathrm{H}$ peak of the pyrrole ring were at around $3444 \mathrm{~cm}^{-1}$, the $\mathrm{C}=\mathrm{C}$ stretching vibration peaks at 


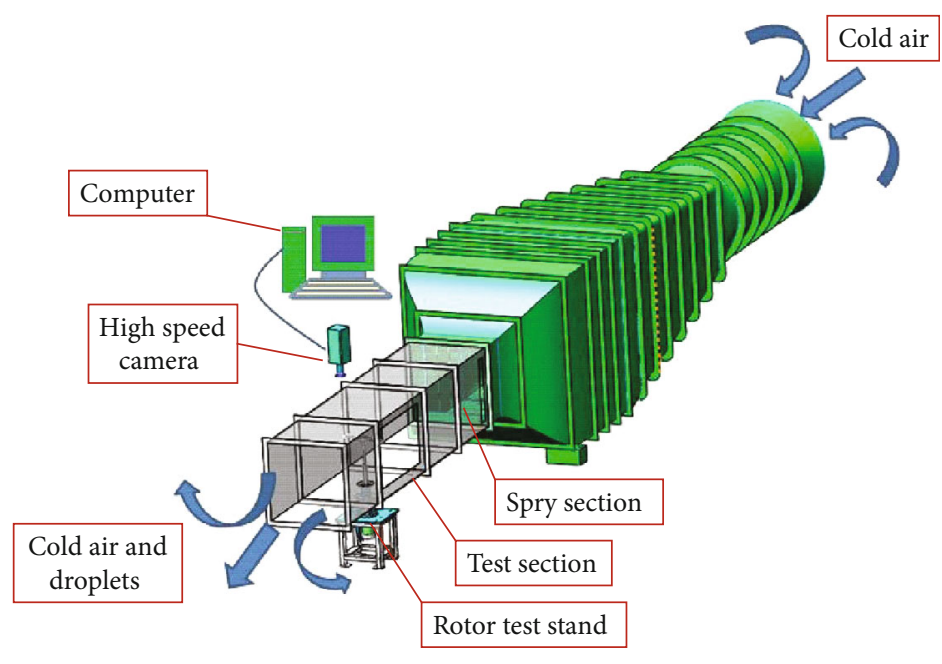

(a) Natural cryogenic wind tunnel

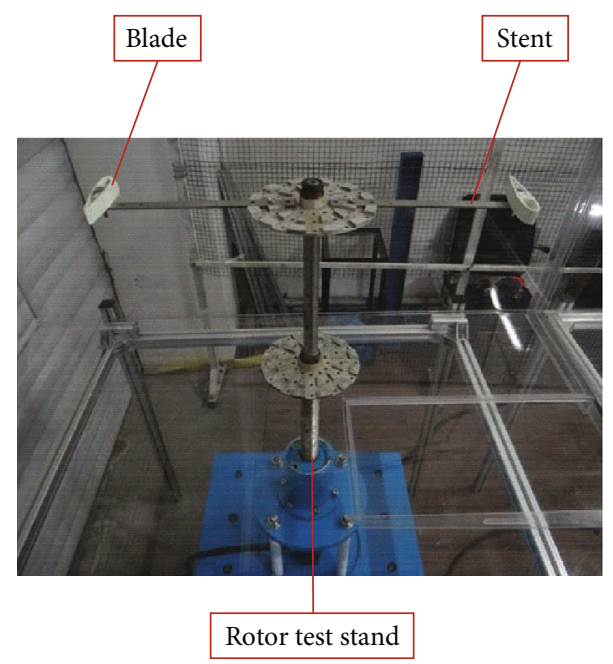

(b) Blade rotation test bench

FIgURE 1: Natural cryogenic wind tunnel system.

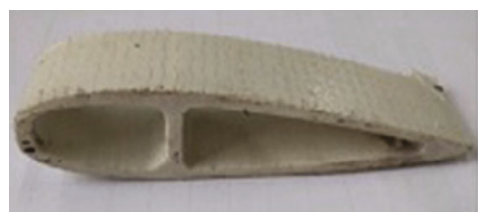

(a) No coating blade

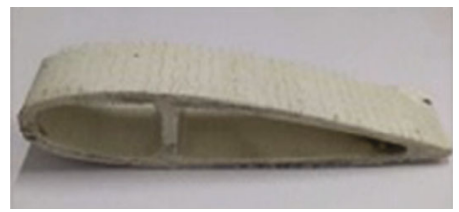

(b) PVDF coating blade

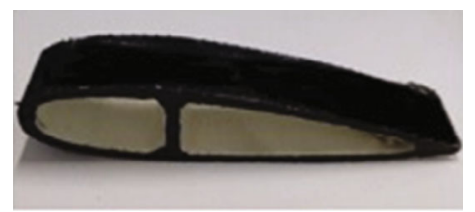

(c) PPY anti-icing coating blade

Figure 2: Blade model.

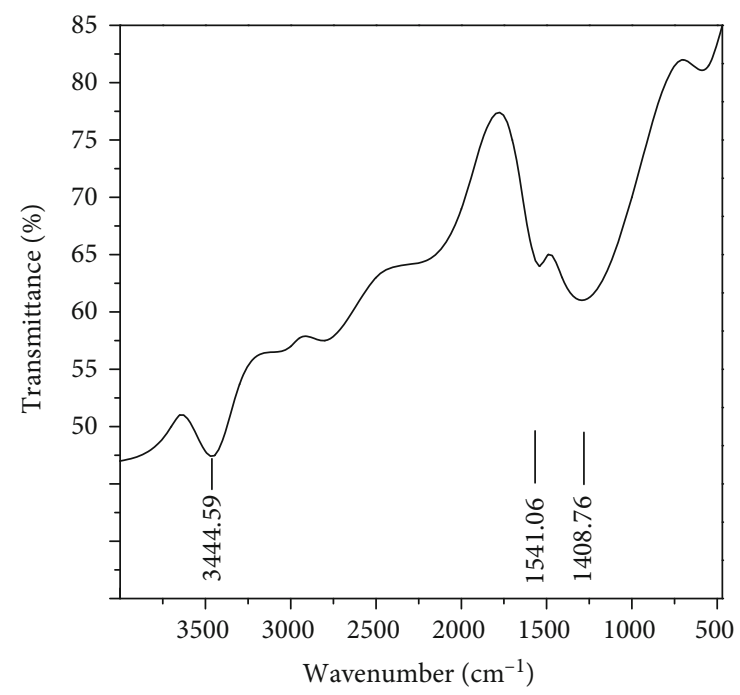

FIGURE 3: Fourier-transform infrared spectroscopy (FTIR) analysis of PPy. the pyrrole ring were at around $1541 \mathrm{~cm}^{-1}$, and the $\mathrm{C}-\mathrm{N}$ expansion vibration peak on the pyrrole ring were at $1338 \mathrm{~cm}^{-1}$. Compared with the standard FTIR spectra of pure PPy $[31,32]$, it can be seen that the positions of the characteristic peaks were basically the same. Thus, we can preliminarily confirm that PPy can be successfully synthesized.

4.2. The Morphology and Microstructure Analysis. The morphology and microstructure of nanomaterials were analyzed by field emission scanning electron microscopy (SU800, HITACHI). Figures 4(a) and 4(b) show the microstructure of the original PPy. It was shown in Figure 4(a) that the synthesized PPy presented a porous form formed by a circular needle and dispersed uniformly. It was known from Figures 4(a) and 4(b) that the diameter of the original linear PPy was about 60-80 $\mathrm{nm}$ and the diameter of the formed hole was about $100 \mathrm{~nm}-300 \mathrm{~nm}$. The surface of the wind turbine blade coated into PPy coating also showed the porous shape of the return rang needles, and its scanning electron microscope is shown in Figure 5 The diameter of the linear PPy coated into the surface of the wind turbine was 


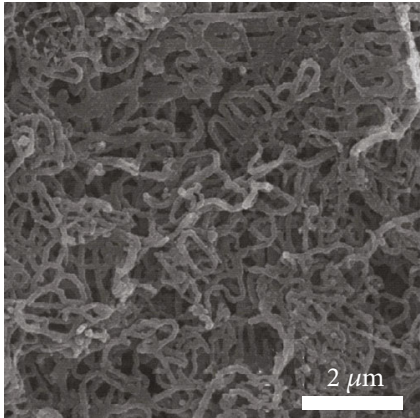

(a) Original PPy

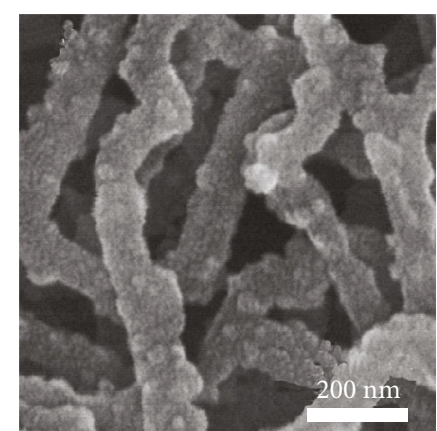

(b) Original PPy HR

FIgURe 4: The microstructure of the original PPy (SEM).

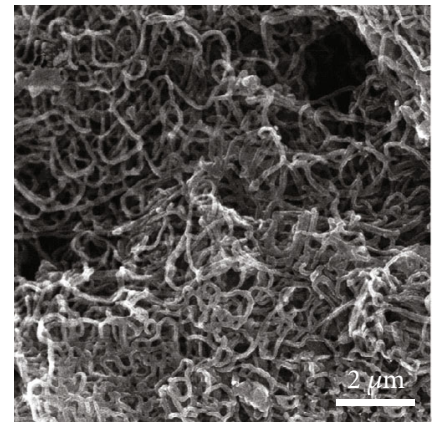

(a) Surface of wind turbine blade coated with PPy coating

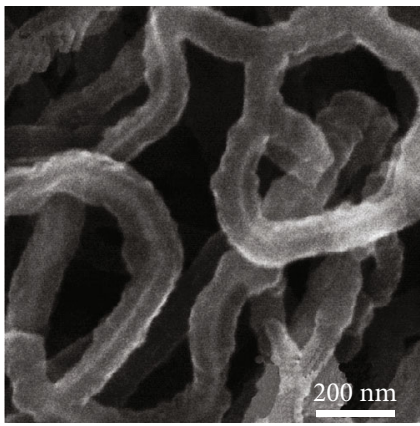

(b) Surface of wind turbine blade coated with PPy coating HRSEM

FIgURe 5: The microstructure of the wind turbine blade surface with PPy coating (SEM).

about $60-80 \mathrm{~nm}$, and the diameter of the formed pore was about $100-300 \mathrm{~nm}$. The dispersion was still very uniform. Due to sufficient time of grinding, stirring, and ultrasonic, it can be seen that PVDF was evenly dispersed, and PVDF has a little effect on the microstructure of PPy.

4.3. The Static Contact Angle Analysis. In order to characterize the wettability of the sample surface, the static contact angle was measured by the video optical contact anglemeasuring instrument (OCA20, Data Physics) with the static drop method. Before coating, the surface of the wind turbine blade was hydrophilic with a water contact angle of $32.3^{\circ}$ (shown in Figure 6). When PVDF was coated on the surface is hydrophobic, and the contact angle of blade surface was $93.4^{\circ}$ (shown in Figure 7). The contact angle reached $127.2^{\circ}$ (shown in Figure 8) after PPy coating, and the hydrophobicity increased greatly. Figure 8 shows the shape of the droplets on this strong hydrophobic coating. The droplets stand on the coating like rain drops on the surface of the lotus leaf, which is easy to fall off because of its low adhesion and strong hydrophobicity. The blade surface of the wind turbine coated into PPy coating was porous and rough. In theory, air can be trapped in these pores. Therefore, the rough PPy coating can be regarded as a composite composed of air and PPy trapped in the pores, which can be described by the Cassie-Baxter model [33].

$$
\cos \theta_{r}=f_{1} \cdot \cos \theta-f_{2} .
$$

Here, the contact fraction of water and strong hydrophobic PPy coating surface and the contact fraction between water and air are $f_{1}$ and $f_{2}$, respectively; the equilibrium contact angle on the blank blade surface is $\theta$. It is predicted by the equation that the contact angle $\left(\theta_{r}\right)$ of PPy coating will be increased by increasing $f_{2}$; in addition, the contact angle $\left(\theta_{r}\right)$ of PPy coating will be decreased when $f_{1}$ increases. Based on contact angle data $\theta_{r} 127.2$, the equilibrium contact angle $\theta$ is $32.3^{\circ}$. So according to formula (1), we got

$$
\cos 127.2^{\circ}=f_{1} \cdot \cos 32.3^{\circ}-\left(1-f_{1}\right) .
$$

Therefore, $f_{1}$ was calculated to be about $21.4 \%$. This means that about $78.6 \%$ of the air interception area exists when the coarse PPy coating contacted with the water droplets. The results showed that most of the water droplets did not infiltrate into the gap but on the surface of the coating, and the water droplets were basically in contact with each other, thus ensuring that the coating surface has a large contact angle. Because the surface coated with PPy has a micronanostructure similar to the surface of the lotus leaf and the data obtained from the contact angle measurement, we think that the surface microstructure of PPy coating leads to its strong hydrophobic properties.

4.4. Variation of Icing Weight and Comparison of Maximum Icing Thickness. In order to study the ice-forming process of dynamic water droplets and the anti-icing effect of the coating, the dynamic icing experiments were carried out in a 

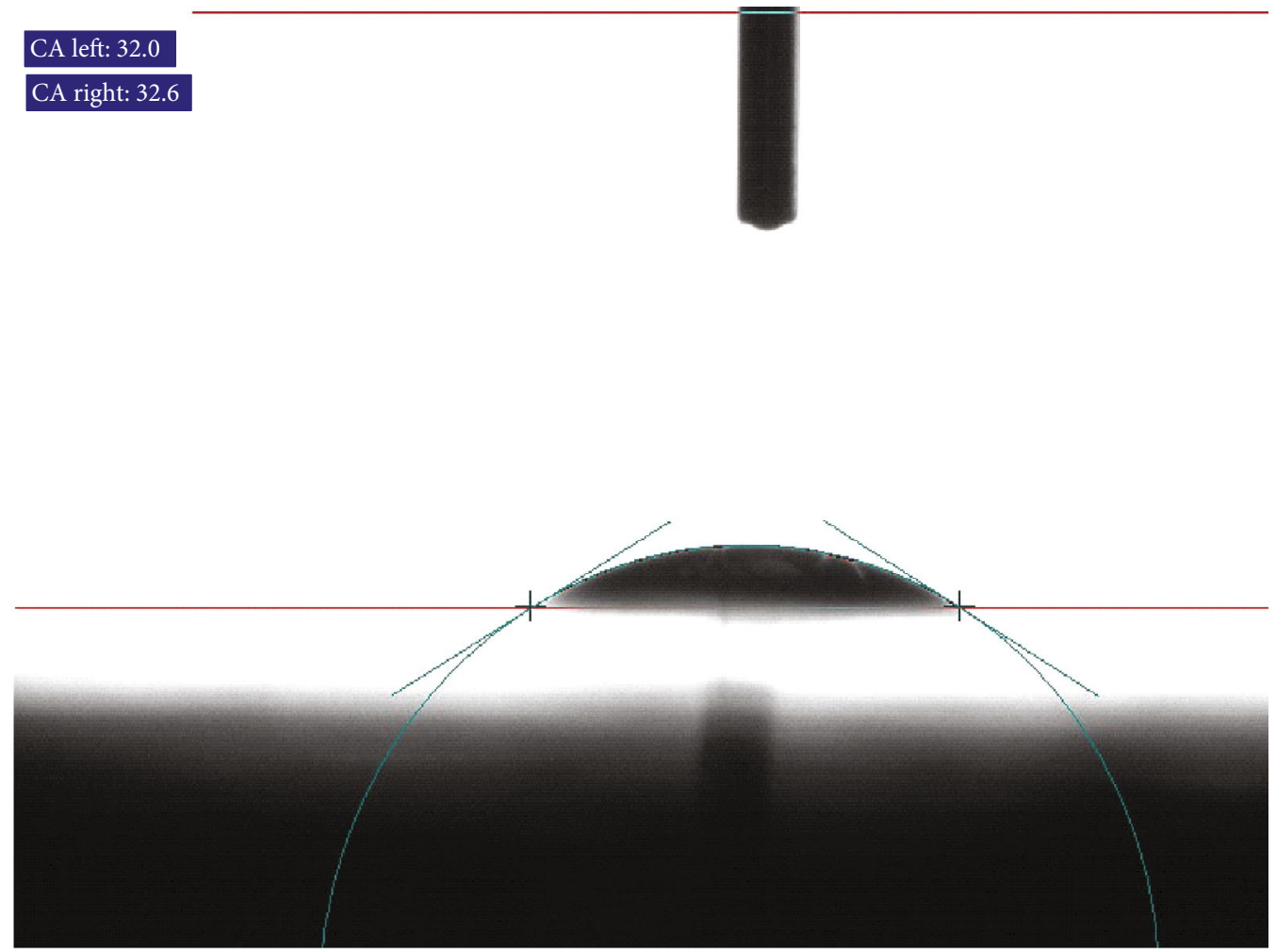

FIgURE 6: Contact angle and water droplet shape of wind turbine blade without coating.

\section{CA left: 94.6 \\ CA right: 92.2}

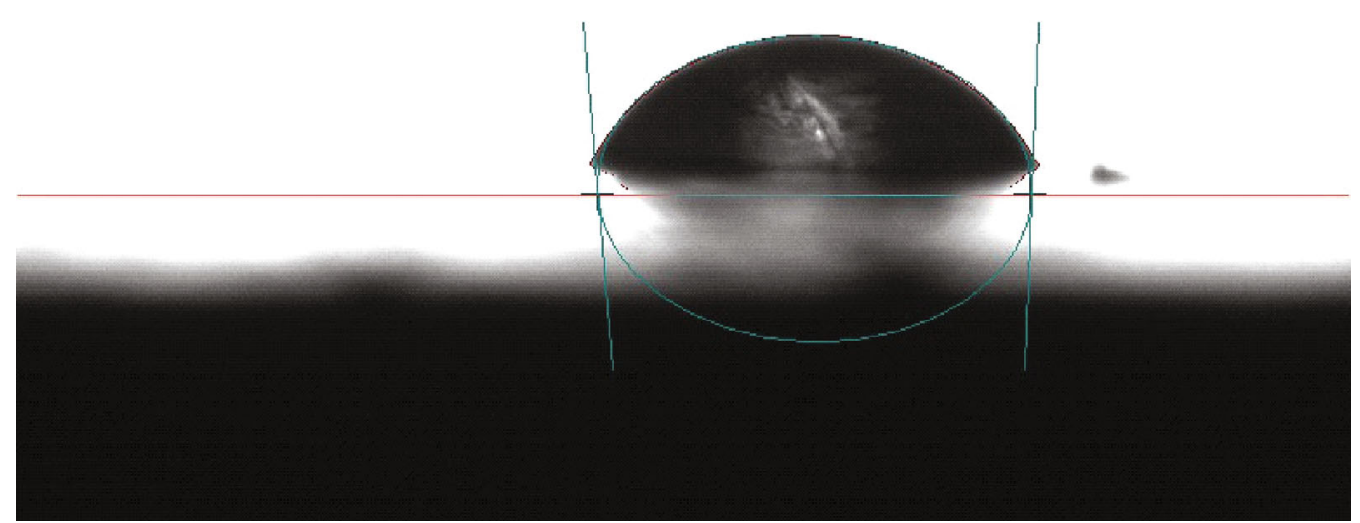

FIGURE 7: Contact angle and water droplet shape of wind turbine blade coated with PVDF coating. 


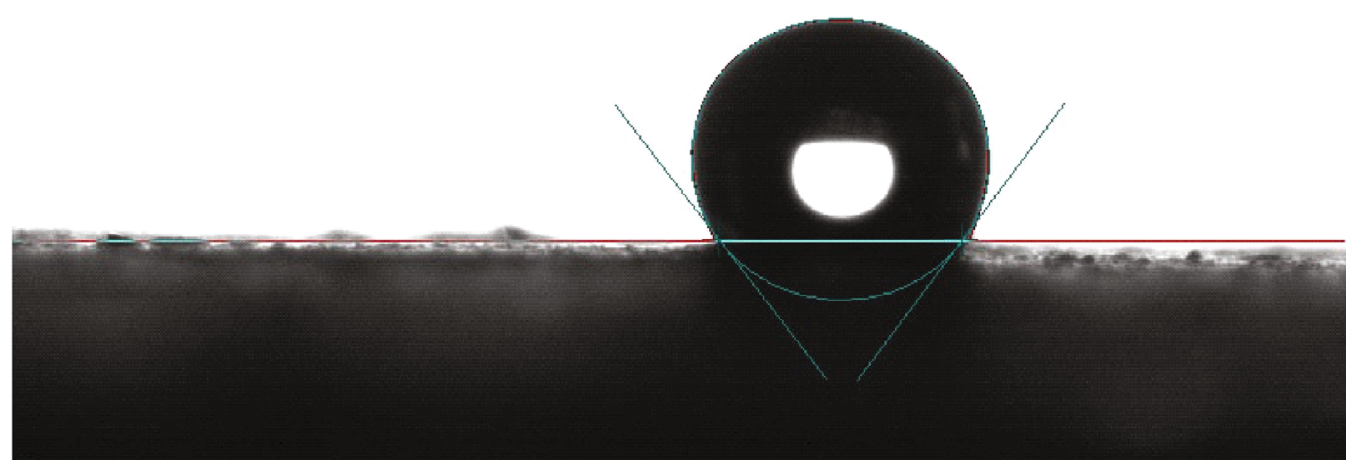

FIgURE 8: Contact angle and water droplet shape of wind turbine blade coated with PPy coating.

TABLE 1: Variation of ice in three models.

\begin{tabular}{lccc}
\hline $\begin{array}{l}\text { Time } \\
(\mathrm{s})\end{array}$ & $\begin{array}{c}\text { No coating blade } \\
(\mathrm{g})\end{array}$ & $\begin{array}{c}\text { PVDF coating } \\
\text { blade }(\mathrm{g})\end{array}$ & $\begin{array}{c}\text { PPY coating } \\
\text { blade }(\mathrm{g})\end{array}$ \\
\hline 0 & 0.00 & 0.00 & 0.00 \\
10 & 2.90 & 2.70 & 0.01 \\
20 & 5.04 & 4.60 & 0.03 \\
30 & 8.66 & 7.45 & 0.02 \\
40 & 11.99 & 11.00 & 0.05 \\
50 & 23.75 & 20.40 & 0.10 \\
60 & 26.13 & 25.00 & 0.10 \\
\hline
\end{tabular}

natural cryogenic wind tunnel on the uncoated blade surfaces, the blade surface coated with PVDF coatings, and the blade surface coated with PPy coatings. The test model was installed on the blade rotation test-bed, the working mode of vertical axis wind turbine, and the blade rotation radius was $300 \mathrm{~mm}$.

The test temperature of the natural cryogenic wind tunnel system was $-6^{\circ} \mathrm{C}$. The supercooled water droplets with a temperature of $0^{\circ} \mathrm{C}$ were sprayed on the sample surfaces through sprinklers with a pore diameter of $1 \mathrm{~mm}$. The supercooled air inhaled by the wind tunnel was mixed with water mist, then ejected from the wind tunnel opening and impacted on the surface of the blade of the wind turbine. The outlet wind speed wind tunnel was $6 \mathrm{~m} / \mathrm{s}$ with the angle of attack of the blade airfoil of 0 degrees, and the speed was $100 \mathrm{r} / \mathrm{min}$. According to reference [34], the LWC was

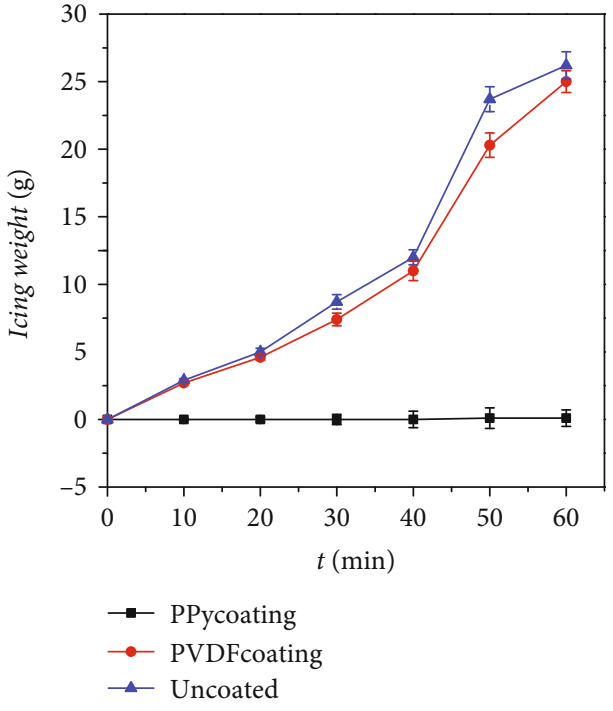

Figure 9: The comparison results of icing change on three blade surfaces.

$0.58 \times 10^{-3} \mathrm{~g}$. The MVD was $50 \mu \mathrm{m}$. The atmospheric pressure was $101.325 \mathrm{~Pa}$. In order to evaluate the ice proof and ice accumulation of the sample, the blade was weighed after every 10 seconds.

4.4.1. Variation of Icing Weight. Use the analytical balance with an accuracy of 0.01 to weigh the three coating models 

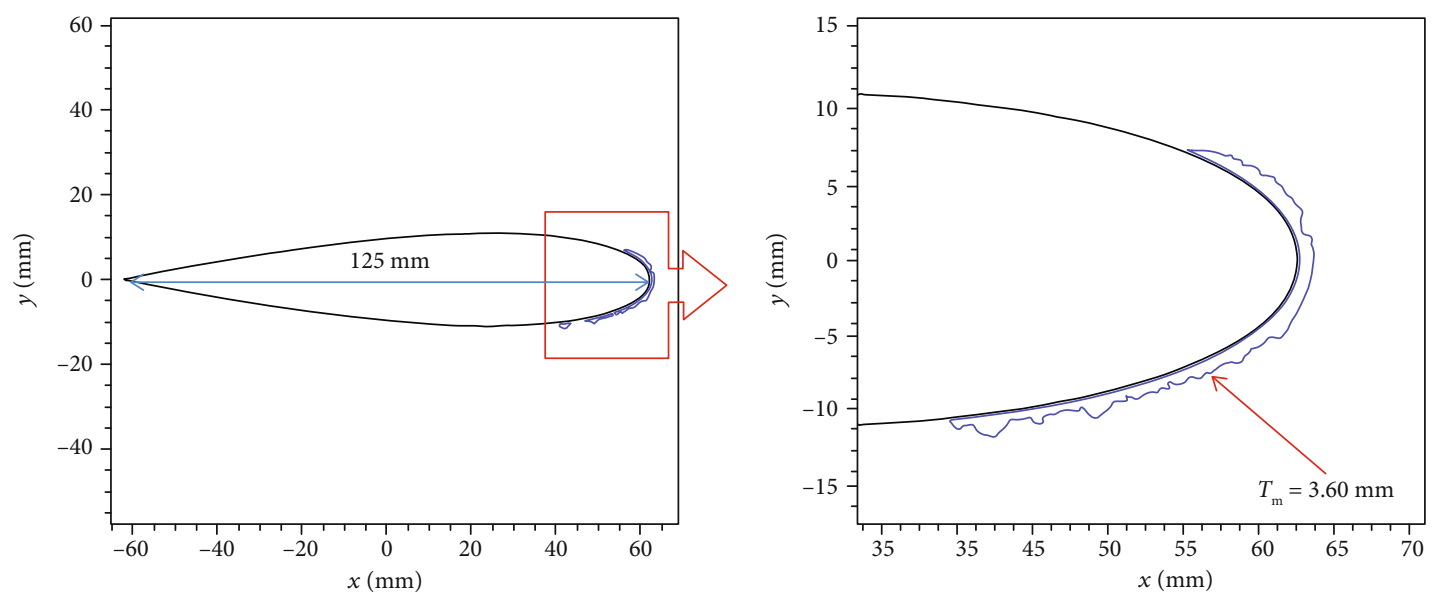

_ Airfoil

(a) No coating blade

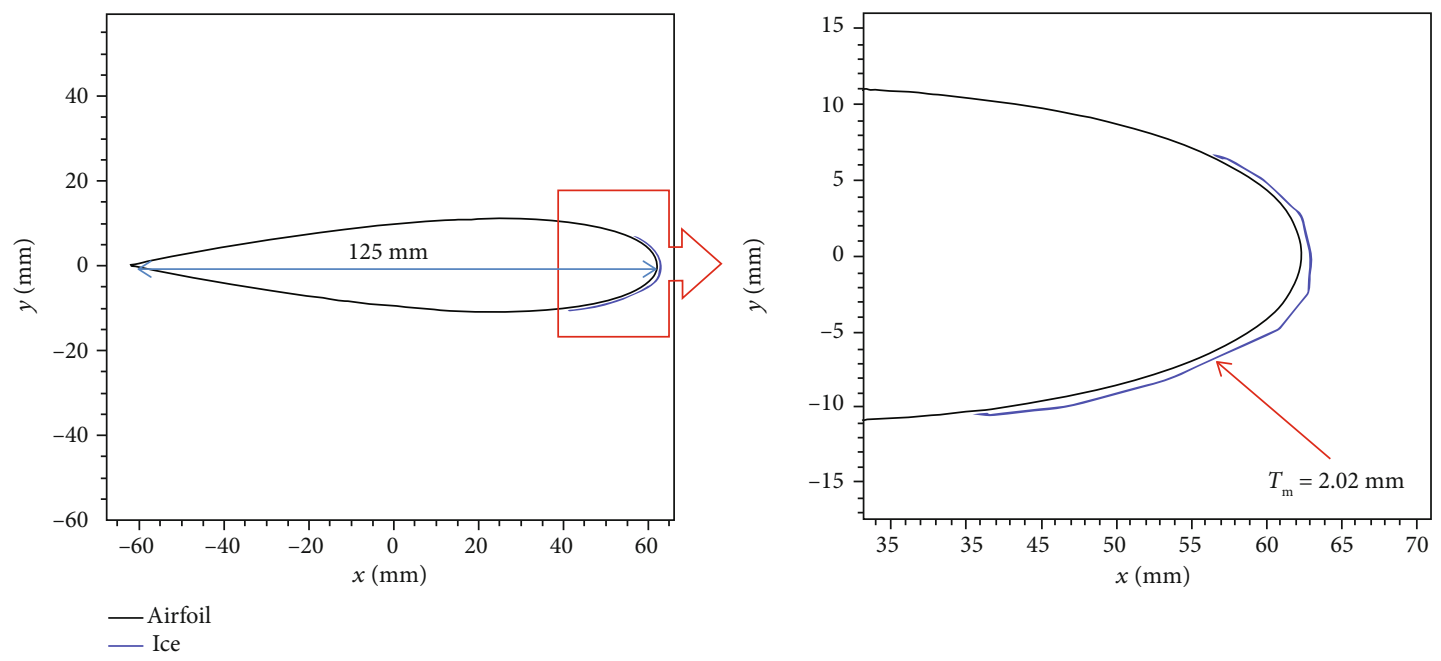

(b) PVDF coating blade
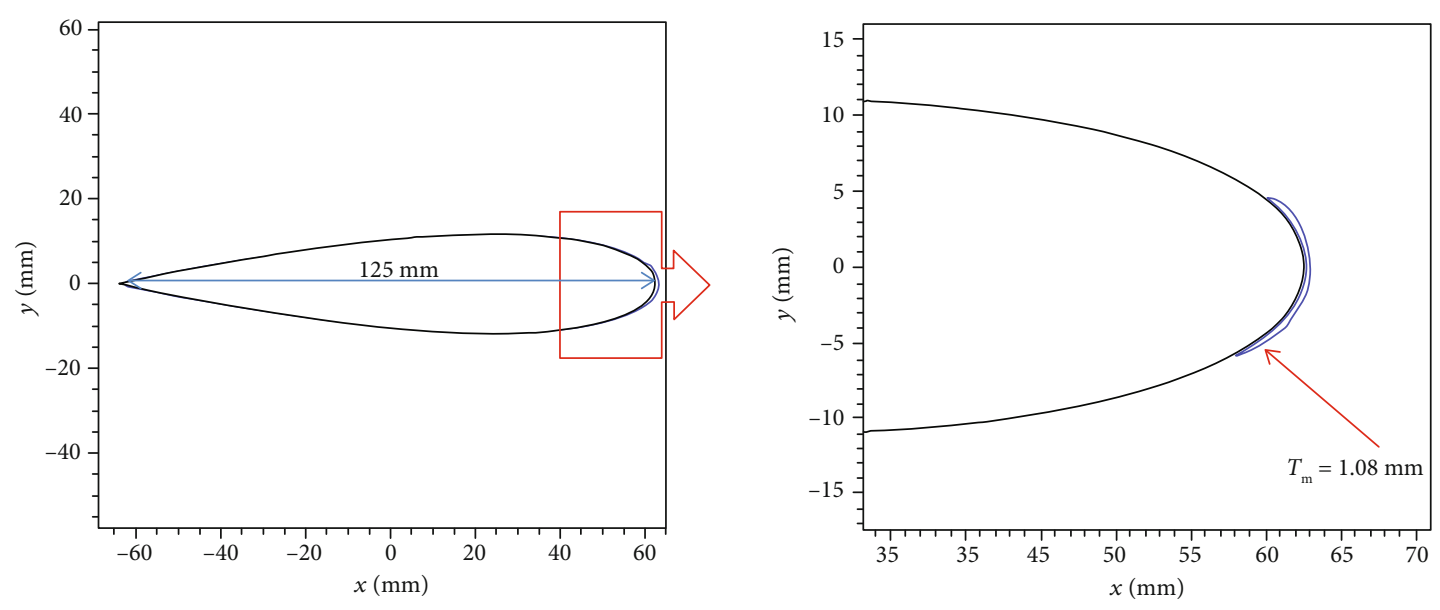

$$
\text { —Airfoil }
$$

(c) PPY anti-icing coating blade

FIGURE 10: The results of icing on three kinds of blade surfaces. 
before and after freezing, and then use the weight difference to obtain the icing amount of the three coating models. Repeat the test three times, and the average results of the icing changes of the three coating models are shown in Table 1.

It can be found from Table 1 that there were differences in the mass of icing on the blade surface. The ice thickness of the blade surface coated into PPy coatings was small according to the definition of ice type in reference [35]; it can be seen that the type of ice generated was rime ice.

The comparison in the variation of icing weight of three blade surfaces is shown in Figure 9. It can obviously be illustrated with Figure 9 that the weight of hydrophilic wind turbine blade without any coating increases linearly during the test time and that of hydrophobic PVDF coating blade increases linearly, but the increase range was lower than that of the uncoated blade. The maximum icing weight of strong hydrophobic PPy coating blade was almost $0.10 \mathrm{~g}$. The maximum icing weight of no coating blade was almost $26.13 \mathrm{~g}$.

4.4.2. Comparison of Maximum Icing Thickness. Through the ice pattern images of three kinds of coating models after icing, we found the overall icing image of the three kinds of blades and the enlarged contrast image of local icing, as shown in Figure 10. The maximum ice thickness $T_{m}$ on the surface was measured at the position of the thickest icing on the leading edge of the three kinds of blades. That is, the no coating blade was $3.60 \mathrm{~mm}$, PVDF coating blade was $2.02 \mathrm{~mm}$, and PPY anti-icing coating blade was $1.08 \mathrm{~mm}$. It can be seen that the maximum icing thickness of PPY coating was the smallest and has a better anti-ice effect.

\section{Conclusion}

Based on the analysis of surface morphology and wetting properties, it can be concluded that the surface structures has a great influence on the freezing properties of watering droplets on the surface under the experimental conditions in this paper. The water contact angle of strong hydrophobic PPy coatings was $127.2^{\circ}$. Strong hydrophobic PPy coatings exhibit excellent anti-icing properties. The maximum icing weight of a strong hydrophobic PPy coating blade was almost $0.10 \mathrm{~g}$. The maximum icing weight of no coating blade was almost $26.13 \mathrm{~g}$. The maximum icing thickness of strong hydrophobic PPy coating blade was only $1.08 \mathrm{~mm}$.

The strong hydrophobic PPy nanocoatings prepared for the wind turbine blades have excellent anti-icing performance. This has important reference significance and practical value for the design and preparation of anti-icing coating for wind turbine blades.

\section{Data Availability}

I would like to share the data underlying the findings of my manuscript. The data used to support the findings of this study are included within the article. Readers can access the data supporting the conclusions of the study.

\section{Conflicts of Interest}

The authors declare that they have no conflicts of interest.

\section{Acknowledgments}

This research is sponsored by the project supported by Open Foundation of Key Laboratory of Icing and Anti/De-Icing of Aircraft (AIADL20180303) and the project also supported by the National Natural Science Foundation of China (NSFC) (51576037). The authors give thanks to their supporters.

\section{References}

[1] J. Zeng and B. Song, "Research on experiment and numerical simulation of ultrasonic de-icing for wind turbine blades," Renewable Energy, vol. 113, pp. 706-712, 2017.

[2] L. Yan, S. Ce, J. Yu, and F. Fang, "Scaling method of the rotating blade of a wind turbine for a rime ice wind tunnel test," Energies, vol. 12, no. 4, p. 627, 2019.

[3] R. Menini, Z. Ghalmi, and M. Farzaneh, "Highly resistant icephobic coatings on aluminum alloys," Cold Regions Science and Technology, vol. 65, no. 1, pp. 65-69, 2011.

[4] A. G. Kraj and E. L. Bibeau, "Measurement method and results of ice adhesion force on the curved surface of a wind turbine blade," Renewable Energy, vol. 35, no. 4, pp. 741-746, 2010.

[5] S. Hong, R. Wang, X. Huang, and H. Liu, "Facile one-step fabrication of PHC/PDMS anti-icing coatings with mechanical properties and good durability," Progress in Organic Coatings, vol. 135, pp. 263-269, 2019.

[6] C. Antonini, M. Innocenti, T. Horn, M. Marengo, and A. Amirfazli, "Understanding the effect of superhydrophobic coatings on energy reduction in anti-icing systems," Cold Regions Science and Technology, vol. 67, no. 1-2, pp. 58-67, 2011.

[7] C. Peng, S. Xing, Z. Yuan, J. Xiao, C. Wang, and J. Zeng, "Preparation and anti-icing of superhydrophobic PVDF coating on a wind turbine blade," Applied Surface Science, vol. 259, no. 41, pp. 764-768, 2012.

[8] B. Liang, G. Zhang, Z. Zhong, Y. Huang, and Z. Su, "Superhydrophilic anti-icing coatings based on polyzwitterion brushes," Langmuir, vol. 35, no. 5, pp. 1294-1301, 2019.

[9] S. A. Kulinich and M. Farzaneh, "On ice-releasing properties of rough hydrophobic coatings," Cold Regions Science and Technology, vol. 65, no. 1, pp. 60-64, 2011.

[10] C. Li, X. Li, C. Tao et al., "Amphiphilic antifogging/anti-icing coatings containing POSSPDMAEMA-b-PSBMA," ACS Applied Materials \& Interfaces, vol. 9, no. 27, pp. 2295922969, 2017.

[11] Z. Huang, Prepatation and anti-icing performances of durable superhydrophobic/semiconducting composite silicone rubber coatings, Chongqing University, 2016.

[12] L. Yin, Q. Xia, J. Xue, S. Yang, Q. Wang, and Q. Chen, “In situ investigation of ice formation on surfaces with representative wettability," Applied Surface Science, vol. 256, no. 22, pp. 6764-6769, 2010.

[13] P. Tourkine, M. Le Merrer, and D. Quéré, "Delayed freezing on water repellent materials," Langmuir, vol. 25, no. 13, pp. 72147216, 2009.

[14] Z. Qiaolan, M. He, J. Chen, J. Wang, Y. Song, and L. Jiang, "Anti-icing surfaces based on enhanced self-propelled 
jumping of condensed water microdroplets," Chemical Communications, vol. 49, no. 40, pp. 4516-4518, 2013.

[15] X. Xiao, G. Cao, F. Chen, Y. Tang, X. Liu, and W. Xu, "Durable superhydrophobic wool fabrics coating with nanoscale $\mathrm{Al}_{2} \mathrm{O}_{3}$ layer by atomic layer deposition," Applied Surface Science, vol. 349, pp. 876-879, 2015.

[16] J. J. Victor, D. Facchini, and U. Erb, "A low-cost method to produce superhydrophobic polymer surfaces," Journal of Materials Science, vol. 47, no. 8, pp. 3690-3697, 2012.

[17] C. Su, "A simple and cost-effective method for fabricating lotus-effect composite coatings," Journal of Coating Technology and Research, vol. 9, no. 2, pp. 135-141, 2012.

[18] I. Sotiri, J. C. Overton, A. Waterhouse, and C. Howell, "Immobilized liquid layers: a new approach to anti-adhesion surfaces for medical applications," Experimental Biology and Medicine, vol. 241, no. 9, pp. 909-918, 2016.

[19] L. Cao, A. K. Jones, V. K. Sikka, J. Wu, and D. Gao, “Anti-icing superhydrophobic coatings," Langmuir, vol. 25, no. 21, pp. 12444-12448, 2009.

[20] D. K. Sarkar and M. Farzaneh, "Superhydrophobic coatings with reduced ice adhesion," Journal of Adhesion Science and Technology, vol. 23, no. 9, pp. 1215-1237, 2009.

[21] T. Bharathidasan, S. V. Kumar, M. S. Bobji, R. P. S. Chakradhar, and B. J. Basu, "Effect of wettability and surface roughness on ice-adhesion strength of hydrophilic, hydrophobic and superhydrophobic surfaces," Applied Surface Science, vol. 314, no. 31, pp. 241-250, 2014.

[22] Z. Han, J. Fu, X. Feng, S. Niu, J. Zhang, and L. Ren, "Bionic anti-adhesive electrode coupled with maize leaf microstructures and TiO2coating," RSC Advances, vol. 7, no. 72, pp. 45287-45293, 2017.

[23] T. Cebeci and F. Kafyeke, "AIRCRAFTICING," Annual Review of Fluid Mechanics, vol. 35, no. 1, pp. 11-21, 2003.

[24] Federal Aviation Administration, "Capabilities and Prospects for Improvement in Aircraft Icing Simulation Methods: Contributions to the $11 \mathrm{C}$ Working Group," in DOT/FAA/AR01/28, Federal Aviation Administration, 2001.

[25] M. G. Potapczuk and J. J. Reinmann, Icing simulation: a survey of computer models and experimental facilities, NASA, United States, 1991.

[26] C. D. Macarthur, "Numerical simulation of airfoil ice accretion," in 21st Aerospace Sciences Meeting, Reno, NV, U.S.A, January 1983.

[27] M. G. Potapczuk, "A review of NASA Lewis' development plans for computational simulation of aircraft icing," in 37th Aerospace Sciences Meeting and Exhibit, Reno, NV, U.S.A, January 1999.

[28] S. Gouttebroze, F. Saeed, and I. Paraschivoiu, Canice - capabilities and current statusNATO/RTO Workshop, CIRA in Capua, Italy, December 2000, http://www.researchgate.net/publication/ 228932401_Ice_Accretion_Simulation_Code_CANICE.

[29] M. T. Brahimi, D. Chocron, and I. Paraschivoiu, "Prediction of ice accretion and performance degradation of HAWT in cold climates," in 1998 ASME Wind Energy Symposium, Reno, NV, U.S.A, January 1998.

[30] Q. T. Dong, Z. Y. Jin, and Z. G. Yang, "A review of icing effect on horizontal axis wind turbine," Machinery Design \& Manufacture, vol. 10, pp. 269-272, 2014.

[31] Y. Gao, B. He, M. Xiao, Z. Fang, and K. Dai, "Study on properties and mechanisms of luminescent cement-based pavement materials with super-hydrophobic function," Construction and Building Materials, vol. 165, pp. 548-559, 2018.

[32] M. Omastová, M. Trchová, J. Kovářová, and J. Stejskal, “Synthesis and structural study of polypyrroles prepared in the presence of surfactants," Synthetic Metals, vol. 138, no. 3, pp. 447-455, 2003.

[33] A. B. D. Cassie and S. Baxter, "Wettability of porous surfaces," Transactions of the Faraday Society, vol. 40, no. 1, pp. 546-551, 1944.

[34] L. I. Yan, W. A. N. G. Shaolong, and Z. H. E. N. G. Yufang, "Design of wind tunnel experiment system for wind turbine icing by using natural low temperature," Journal of Experiments in Fluid Mechanics, vol. 30, no. 2, pp. 54-58, 2016.

[35] Y. Han, J. Palacios, and S. Schmitz, "Scaled ice accretion experiments on a rotating wind turbine blade," Journal of Wind Engineering and Industrial Aerodynamics, vol. 109, pp. 5567, 2012. 